\title{
A Review on Medical Devices and Imaging
}

\author{
Sapna S Gangolli ${ }^{1}$, Harinee $\mathbf{P}^{2}$ \\ UG - Biomedical Engineering, Dr.N.G.P Institute Of Technology, Coimbatore, Tamil Nadu
}

\begin{abstract}
As early as 2000 to 5000 years ago, several traditional civilizations used tools like extractors, knives, scalpels, saws, lancets, needles, trocars and knives for many medical procedures. From the first century to the seventeenth century, most medical procedures were concerned with the treatment of injuries of troopers at war on the battlefields, or the ailments of the fortunate and wealthy. Devices were meant to treat field wounds received from arrows, knives, sabres, guns and cannons. With the rationalization of the methodology within the seventeenth century, such devices became additionally prevailing. Several medical devices were factory-made by doctors or tiny corporations and imposed on to the general public with no government standards or oversight for safety or effectiveness. Advances were created within the areas like medicine, optometry, prostheses, catheterization with devices like syringes for removal of cataracts, eyeglasses, bimetal or wood artificial limbs and bimetal catheters. The thought of medical imaging began in 1895 with the invention of the X-ray by a German academic of Physics, Wilhelm Roentgen. Medical imaging has improved vastly since the primary X-rays were made appropriate. There's rather more accuracy in diagnosis and since those advances, there's additionally a lot less ought to perform primary surgery. This hopefully can result in early diagnoses and higher treatment choices for several patients. Enhancements were created with the use of technology over the last a hundred years culminating in PC pictorial representation and complicated imaging process. Alternative devices to make highquality and 3-D medical pictures have additionally been developed in the recent years to make medical imaging an awfully vital facet of clinical care these days. In the long run it is usually a tough task, however the electronic health record can play a vital role in consolidating the knowledge and data from numerous medical devices that still provide data promptly on the market to patients where it'd be required. Future medical devices must not solely address issues of diagnostic and therapeutic drugs however even be capable of addressing vital social problems like worldwide disparities within the accessibility of treatment, frequently rising prices, and healthcare for travel beyond Earth. The next 100 years promises to be even more exciting from the perspective of medical devices and medical electronics.
\end{abstract}

Keywords—-Medical devices, Medical imaging, Diagnosis, Healthcare, Technology

\section{INTRODUCTION}

The health care and medical device sectors have grown considerably within the last decade. At present, several medical device manufacturers (domestic and international) chase this huge market of medical devices in India as a big chance for growth. The medical device trade is driven by the overall proficiency of the makers with the design method and its numerous needs. The planning method incorporates inherent connection of science and style. The medical device trade is driven by the overall proficiency of the makers with the design method and its numerous needs. The planning method incorporates the inherent connection of each science and style. The clinical success of a style depends not only on its practicality however additionally its technical. Human factors engineering (HFE)-based style provides optimum results like augmented safety, reduced errors, reduced coaching time, and improved task performance. Applied engineering permits designers and engineers to develop data regarding the wants and desires of the users rather than providing solutions to the incorrect issues. New development may be done by improving cross purposeful team communication, the utilization of quality product definition, and performance assessments throughout development. There is a lack of research pertaining to the various factors that influence the medical device design process. The four main factors that are examined in this paper are product development, tissue modeling, training, and following FDA regulations. Medical devices are necessary elements of improving outcome of patients and overall safety, so it's necessary to become aware of however they are designed and developed

\section{WHAT IS A MEDICAL DEVICE?}

A medical device could also be outlined as any appliance, instrument, material, equipment or different equipment, either utilized in a form together with different equipment/devices and with the software essential for its supposed purpose by the manufacturer to be used for the following purpose of: diagnosis, prevention, monitoring, treatment or alleviation of disease

- designation, monitoring, treatment, alleviation or compensation for associated degree injury or handicap

- investigation, replacement or modification of the anatomy or of a physiological method 


\section{DOI: $10.17148 /$ IARJSET.2021.8819}

- management of conception that doesn't achieve its principal supposed action in or on the human body by medicine, immunological or metabolic.

\subsection{Types of medical devices}

Active medical device - Any active medical device that is meant to be wholly or partially introduced, surgically or medically, into the human body or by medical intervention into a natural porta, and that is meant to stay once the procedure is over.

Active implantable medical device - Any active medical device which is intended to be totally or partially introduced, surgically or medically, into the human body or by medical intervention into a natural orifice, and which is intended to remain after the procedure.

In vitro diagnostic medical device - Any medical device that could be a chemical agent, chemical agent product, calibrator, management material, kit, instrument, apparatus, equipment, or system, whether or not used alone or together supposed by the manufacturer to be utilized in vitro for the examination of specimens, including blood and tissue donations, derived from the physique, alone or primarily for the purpose of providing information:

- regarding a physiological or pathological state concerning a congenital abnormality, or

- to work out the protection and compatibility with potential recipients.

\subsection{How are medical devices designed?}

There has been an analysis conducted examining the medical device methods to the standard methodology. The User Centered Design (UCD) is one amongst the foremost current approaches within the medical device trade, and there has been many analyses done supporting it . UCD shows that this sort of approach focuses on user feedback mechanisms deployed in pre-market and post-market phases of the device lifecycle. We understand that medical device makers will utilize these feedback mechanisms and apply a group of device specific analysis algorithms to effectively flag design flaws and help make future designs. UCD techniques facilitate to optimize designs and limitations of device users, that permits developers to foresee these changes however it is possible to work with the device and avoid assumptions which will not mirror the context of use. The feedback from users is one of the most important components of medical device design efforts. Some effective methods for gathering this feedback include prototyping, cognitive walkthrough, interviews, and usability testing. Usability testing may be a technique that's ofttimes used for style validation and is also a cornerstone of best practices for the design of medical devices. The usability targets values that ought to be established with input from users through marketing research techniques like surveys, interviews, and focus teams.

\subsection{Development of products}

Product development plays a vital role and contains an important influence on medical device style. The management of innovation and the connected processes of the recent new product development (NPD) can play a key role within the future success of the medical device trade. The research shows that product success is said to understand user desires, attention to promote ideas, potency in development, effective use of outdoor technology and management of authority. It has also been researched that product success was notably influenced by the predevelopment activities as well as preliminary market assessment and technical analysis beside skilful NPD wherever client integration was enforced throughout the first stages of development. The quantity of your time needed for development is certainly a vital component to device makers. This is often used wherever the thought of time-to-market becomes essential as a result of it's the last word gauge for the business success of a replacement product. It has also shown that it is fascinating to cut back time-to-market to the maximum amount as an advantage while not accreting further development prices, however this is often not associated simply as a goal for all device makers Some device makers utilize a standard design framework throughout development to facilitate this method. This conveys that the standard framework aims to include style variables and criteria that measures distinctive medical domains to facilitate reliable operation, easier maintenance, and quicker development time.

\subsection{Modeling tissues}

Tissue modeling is another vital component that encompasses an important influence on medical device style. The modeling of soft tissue is with reference to medical device style that is usually soft tissue deformation. It's vital to understand however a tool can move with human tissue throughout the method so as to keep up the safety of the patient. Usability testing of medical devices typically needs a surrogate for the human that change usability testing while not putt folks in danger. One of the foremost current models used for human soft tissue is that the mass-spring system (MSS). The most important plan of MSS is to discretize the simulated object with lots between that composite linear elastic spring model is additionally adopted. The particle is constraint to each snap from the spring and therefore the damping force that is proportional with rate. MSS has the benefits of quick computing, straightforward implementation, low machine quality, and higher ability to adapt the changes of soft tissue topology

\subsection{Training}

Training of the health practitioners is another issue that has to be taken into thought throughout device design. These practitioners are those that use the devices most often, in order to be able to operate them fairly and simply produce effective patient care. There has been analysis conducted that planned computer assisted learning could be a viable 
Vol. 8, Issue 8, August 2021

\section{DOI: $10.17148 /$ IARJSET.2021.8819}

answer, which may give considerably superior facilities, each in presenting information, and additionally assessing and recording the performance of trainees. Some factors that have to be thought of for coaching programs embrace accuracy and interrelation of knowledge, quality of presentation, easy comprehension of the code, and accessibility and flexibility of fabric to a range of different ability levels. Surgical coaching is crucial for health practitioners to be ready for the challenges related to actual surgical procedures. It is important that they're comfortable and aware of the devices and instrumentation utilized in these settings so as to own in patient outcomes.

\section{REGULATIONS FORMULATED}

The Centre for Devices and Radiological Health $(\mathrm{CDRH})$ is an organization of the FDA that is responsible for regulating medical devices. The Office of Device Evaluation (ODE) is part of the CDR H and has been placing increased emphasis on expediting its review of marketing applications, which has resulted from the increasing variety of recent technologies that have vital public health advantages additionally as cause overall value savings within the provision of health care. Premarket approval (PMA) is one of the procedures to get marketing clearance, that is needed for brand new technologies that area unit life-supporting, vital, or constituted within the body.

\section{MEDICAL IMAGING MODALITIES}

Medical imaging is home to any or all diagnostic and therapeutic investigations conducted in a typical radiology department. It encompasses totally different imaging modalities and processes to image that builds all diagnostic treatments and follow up functions. It plays a vital role in initiating enhancement of public health for all population groups. Imaging modalities are typically categorised by the tactic with which pictures are generated: ultrasound radiation like X-rays, and MRI. The benefits and limitations of imaging modalities are primarily ruled by theirs essential physical and biological principles that influence the methods that each energy kind interacts with tissues, and by the particular engineering implementation for a specific medical or biological application. Given Below in figure 1, illustrates the timeline of the earliest Medical devices and Imaging techniques being discovered from 1800's.
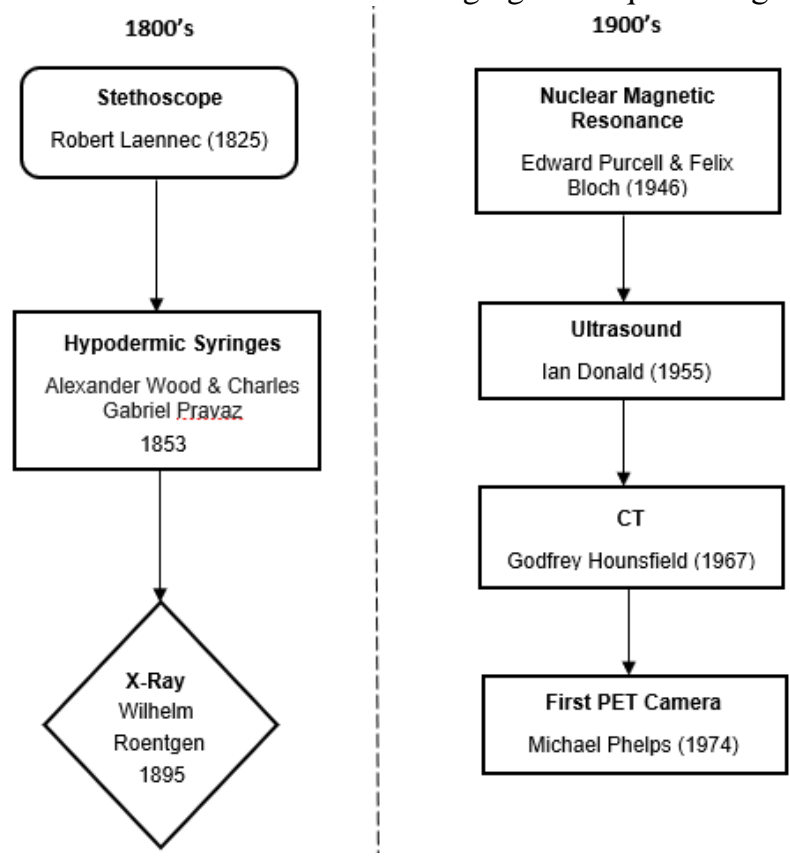

Late 1900's,2000-2019

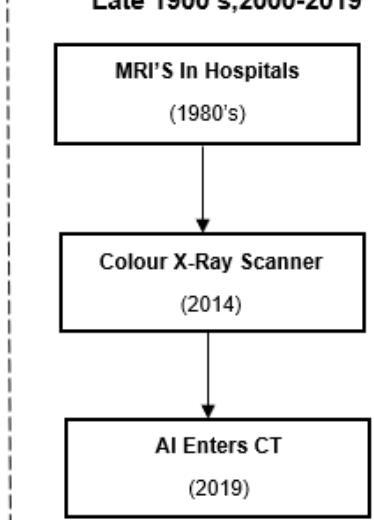

Fig.1. Timeline of the earliest Medical devices and Imaging techniques being discovered from 1800's.

\subsection{X-Ray}

An X-ray is defined as a non-invasive medical check that helps physicians to diagnose and treat medical conditions. Imaging with X-rays involves exposing an area of the body to a low dose of radiation to supply footage within of the body. An X-ray has been the most common imaging modality that has been used for many years.

\subsubsection{Technological development In X-rays}

In the past, tracing and diagnosis in high-risk groups was impossible but the temporal subtraction technique currently permits us to try and do this. In this method, it compares and subtracts a current image from an existing archive image, and any routine follow up would show changes within the risky patient. Image processing software package will find and mark the suspected respiratory organ nodule space. Computer aided Design (CAD) software package is changing into a 


\section{DOI: $10.17148 /$ IARJSET.2021.8819}

widely used analysis common in early prognosis and extra analysis within the field of diagnostic procedure. Radiologists have the chance to receive a 3D picture sequence wherever they will search the system or the channel for structure or the other pathology on this tract.

\subsection{Projection radiography}

This is a quality X-ray imaging technique. A restricted part of the patient's body is irradiated by X-rays that are later attenuated by the various body elements. As the body consists chiefly of water, bones generally show a good and sharp distinction, whereas the distinction exhibited by organs or muscles in X-ray pictures is incredibly restricted. This is the reason why, for specific diagnostic tasks, Iodine(I) or Barium $(\mathrm{Ba})$ distinction agents are injected or swallowed by the patient. Also, their high relative atomic mass of such agents absorbs X-rays greater and therefore enhance the image distinction of tube-shaped structures or the GI tract, for example. The projected image is captured by an X-ray sensitive two-dimensional detector system whereas combos of scintillating foils and film sheets and storage plates are employed in the past.

\subsection{Computed tomography (CT)}

Computed tomography (cross-sectional imaging) is defined as a scanning X-ray imaging procedure that builds a threedimensional dataset of the patient's anatomy by merging individual X-ray projection pictures from totally different directions. A thin, fan-like X-ray beam passes through the patient and is attenuated consistently with the morphology of the body on its pathway. The projection image is registered by a line of separate X-ray detector components. The X-ray tube and the detectors are connected to a frame rotating around the patient. Several projections can be recorded so as to reconstruct two-dimensional picture taking "slices" of the patient's body. As a result of the reconstruction, algorithms are extremely long, they're enforced in contemporary CT systems by special hardware accelerators. There are many scanning techniques together with a single plane, an axial "step and shoot" acquisition, and spiral techniques during which the patient is endlessly moved whereas the frame is rotating. In recent years, CT systems during which the first one-dimensional detector line is replaced by an array of up to 256 lines, consisting of up to 1024 individual detector components (multi-slice CT), thus becoming a standard. These scanners give a far quicker acquisition time, that reduces motion artifacts and improves the work flow. Chest CT analyses the coronavirus malady 2019 (COVID-19) and thisystem allows fast and reliable designation of COVID-19, notably once symptom whose span is bigger than forty-eight hours is noticed. This is shown in the figure 2 given below.

4.4 Magnetic resonance imaging (MRI).

Magnetic Resonance Imaging is defined as a tomographic imaging technique that utilises the Nuclear Magnetic Resonance (NMR) which primarily does imaging using the properties of water protons within the human body. A static flux is applied by Direct Current (DC) coils performed on the patient's body axis. This flux aligns the proton spins. For imaging functions, the alignment is disordered by a brief term RF pulse. The next relaxation of the protons generates another RF signal (NMR signal) that is captured by receiver coils organized round the body region of interest. During a complicated mathematical reconstruction procedure, it is possible to calculate high-resolution pictures from the magnetic resonance signal. Pictures offer an honest distinction between the various soft tissues of the body as a result of the magnetic resonance signal differs for various body tissue densities, e. g. muscles and fat. Tiny gradient field area units are superimposed to outline completely different imaging planes. For special functions like the imaging of vasc
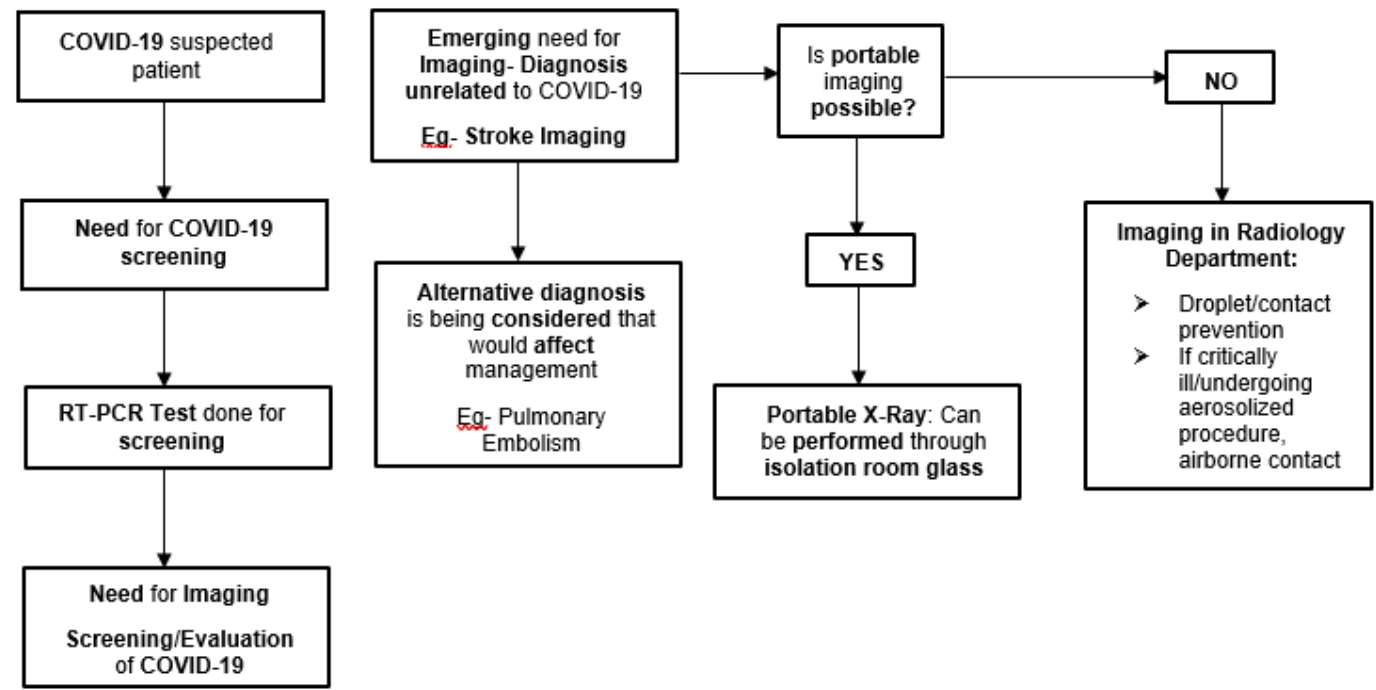

Fig.2. Representing how a CT is done to diagnose COVID-19 in a patient 


\title{
International Advanced Research Journal in Science, Engineering and Technology
}

\author{
Vol. 8, Issue 8, August 2021
}

\section{DOI: 10.17148/IARJSET.2021.8819}

ular structures or tumours, specific distinction agents could also be applied. Present day imaging systems even permits the imaging of moving organs or the beating heart. Besides the quality scanners that seem like an outsized tube, open imaging scanners permit higher access to the patient.

\subsection{Ultrasound imaging}

Ultrasound imaging, or ultrasonography, is a widely applied medical imaging procedure. High-frequency sound waves are applied to an organic structure(tissue) and their mirrored echoes are detected to make a picture. The reflective properties of human tissue rely upon its density. Typically, the shape, size, and structure of organs are often imaged is one in main applications of the MRI (the growing vertebrate). In easy terms, the ultrasound system consists of an electrical device probe, an image signal processing unit and a display. The electrical device unit generates the sound waves and detects their echoes with a collection of piezo-electric quartz crystals. As sound waves are powerfully mirrored at the intersection of media with completely different electric impedance.

\subsection{Nuclear medicine}

In distinction to the imaging techniques mentioned to date, medical imaging applies no external radiation. A distinction agent that is enriched by unstable radionuclides is injected and accumulates in organs or pathological tissue. Later, the $\gamma$ radiation emitted by the radioactive compounds is detected outside the patient's body and a tomography image is reconstructed.

\subsection{Positron-emission tomography (PET)}

In a PET imaging procedure, radiopharmaceuticals consisting of positron-emitting isotopes are applied. Compounds or elements which are also present in the human body are normally chosen because they are easily integrated in body's common metabolism. A major example is the glucose metabolism. Radioactively labelled sugar is injected into the patient and is accumulated in body parts which show a higher rate of glucose metabolism, e. g. malignant cells. PET is a very sensitive method and may also be applied for the imaging of areas which show a very low metabolism, e. g. parts of the heart muscle that are insufficiently supplied with blood after a myocardial infarction.

\subsection{Single photon emission computed tomography (SPECT)}

SPECT is another tomographic imaging principle employed in medical specialties. It generates images that enable body metabolism to be assessed. The radio nuclides used, emit $\gamma$-radiation that is detected by one or additional Gamma-cameras rotating around the body. Compared to PET, SPECT uses radio nuclides that have an extended half-life, and has lower specific resolution and sensitivity. SPECT measures the often-employed techniques in medical specialties, wherever the period for measure is synchronised with the heart beat (gated SPECT).

The above discussed Imaging modalities have various benefits, some of which are discussed below in Table 1

Table.1. Differences between different imaging modalities

\begin{tabular}{|c|c|c|c|}
\hline \multirow{2}{*}{ Basis for comparison } & \multicolumn{3}{|c|}{ X-Ray Vs CT Vs MRI } \\
\hline & X-Ray & $C T$ & MRI \\
\hline Type of Image made & $\begin{array}{l}2-\mathrm{D} \text { images are } \\
\text { created }\end{array}$ & 3-D images are created & 3-D images are created \\
\hline Mode used & Radiation used & $\begin{array}{l}\text { Use of X-Rays } \\
\left(360^{\circ} \text { view }\right)\end{array}$ & $\begin{array}{l}\text { Use of a powerful } \\
\text { magnet and radiation }\end{array}$ \\
\hline $\begin{array}{l}\text { Parts of body being } \\
\text { imaged }\end{array}$ & 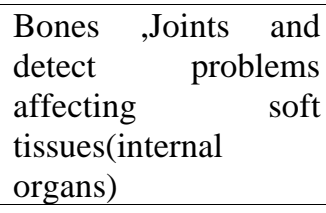 & $\begin{array}{l}\text { General images of } \\
\text { internal organs, complex } \\
\text { bone fractures, trauma }\end{array}$ & $\begin{array}{l}\text { Detailed image of soft } \\
\text { tissues, ligaments and } \\
\text { organs }\end{array}$ \\
\hline $\begin{array}{l}\text { Speed of diagnostic } \\
\text { images }\end{array}$ & $\begin{array}{l}\text { Takes approximately } \\
15 \text { minutes depending } \\
\text { on diagnosis }\end{array}$ & $\begin{array}{l}\text { Quicker than MRI's } \\
\text { (typically } 10-30 \text { minutes } \\
\text { depending on part } \\
\text { scanned) }\end{array}$ & $\begin{array}{l}\text { Takes } 30 \text { minutes or } \\
\text { more to obtain } \\
\text { diagnosis }\end{array}$ \\
\hline Technology trends & $\begin{array}{lr}\text { Multi slice } & \text { detector, } \\
\text { Integration } & \text { of } \\
\text { photodiodes } & \text { and } \\
\text { amplifiers } & \\
\end{array}$ & $\begin{array}{lr}\text { Integration } & \text { of } \\
\text { photodiodes } & \text { and } \\
\text { amplifiers (Example- } \\
\text { CMOS technology) }\end{array}$ & $\begin{array}{l}\text { Open magnets, Fast } \\
\text { registration } \\
\text { techniques, Artifact } \\
\text { compensation }\end{array}$ \\
\hline
\end{tabular}

\section{Medical image processing}

Medical Image processing encompasses the employment and exploration of 3D image datasets of the soma, obtained most typically from a CT or MRI scanner to diagnose pathology or guide medical interventions like surgeries coming up, or for analysis functions. Medical image processing is used by radiologists, engineers, and clinicians to perceive the anatomy of either individual patients or group of patients. 


\section{DOI: 10.17148/IARJSET.2021.8819}

5.1 How does medical image processing work?

The process of medical image processing begins by collecting raw data from CT or any other imaging pictures and reconstructing them into a format appropriate to be used in relevant computer code. A 3D bitmap of greyscale intensities containing a voxel (3D pixels) grid creates the everyday input for image process. CT scan greyscale intensity depends on $\mathrm{X}$-ray absorption, whereas in imaging it's determined by the strength of signals from nucleon particles by relaxation and application of extremely strong magnetic fields.

\subsection{Core areas of medical image processing}

There are numerous concepts and approaches for structuring the field of medical image processing focus on different aspects of its core areas illustrated in Figure 3. These areas form 3 major processes underlying this field-image formation, image computing, and image management. The method of image formation is comprised of information acquisition and image reconstruction steps, providing an answer to a mathematical drawback. The aim of image computing is to boost interpretability of the reconstructed image and extract clinically relevant data from it. Finally, image management deals with compression, archiving, retrieval, and communication of the reconstructed pictures and derived data.

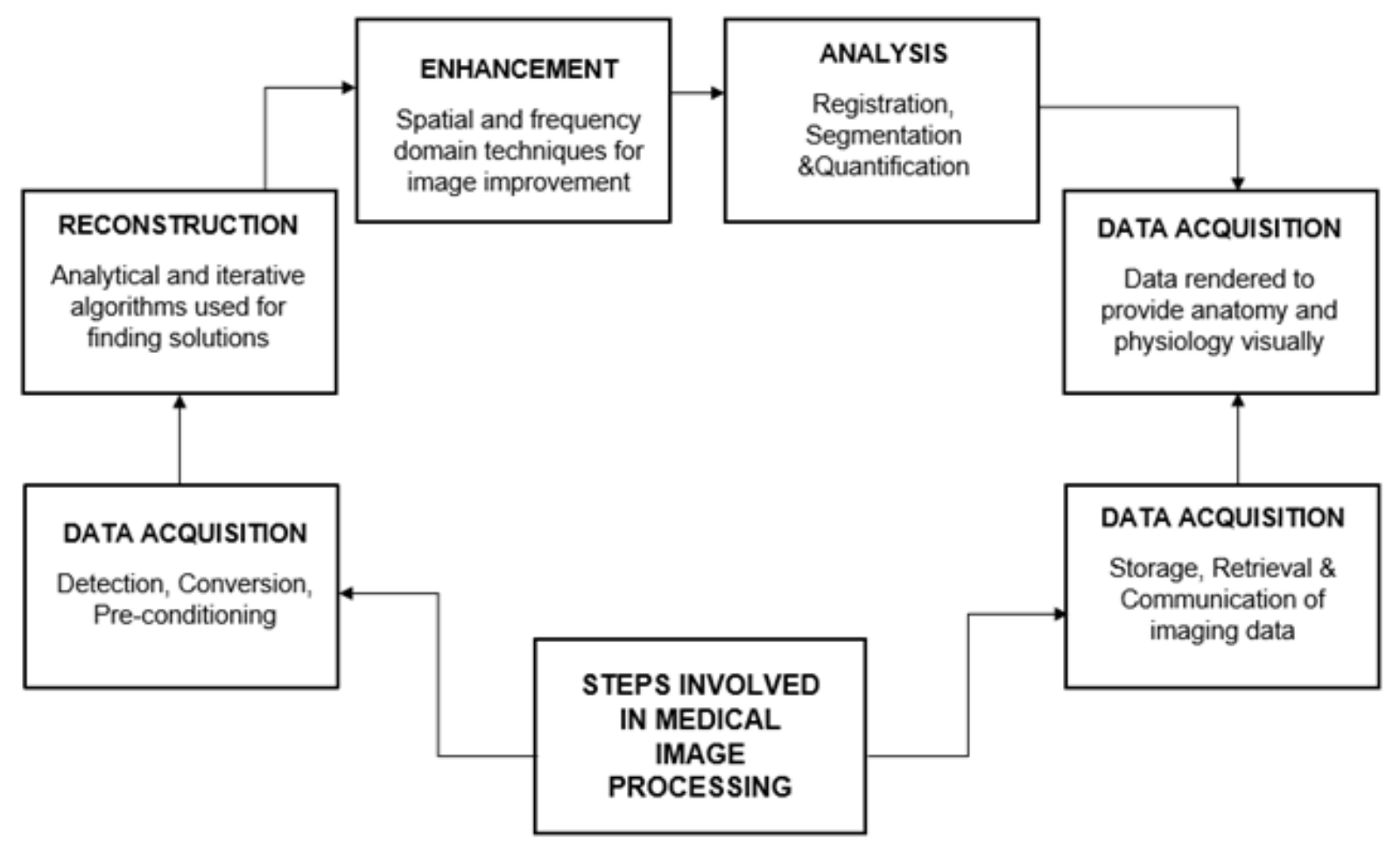

Fig.3. Structural classification of the topic categories in medical image processing.

\subsection{Image formation}

\subsubsection{Data acquisition}

The first integral step within the image formation is dealing with raw imaging information. It contains the first raw data regarding captured physical quantities describing internal aspects of the body. This data becomes the first subject for all ulterior steps of image processing. Various kinds of imaging modalities could utilize completely different physical principles. In Digital Radiography (DR) or Computed Tomography (CT), the energy of incident photons; in Positron Emission Tomography (PET), it's the photons energy and their detection time; in Magnetic Resonance Imaging (MRI), it's the parameters of a radio-frequency signal emitted by the excited atoms; and in Ultrasonography, it's the parameters of the acoustic echoes.

\subsubsection{Image reconstruction}

Image reconstruction is defined as a mathematical operation of forming a picture using raw information/data. For dimensional imaging, this method conjointly includes a mixture of multiple information sets captured at different angles or time steps. A part of medical image processing deals with inverse issues, that may be an elementary subject of the sector. Unvaried algorithms overcome those limitations to make vital improvements in noise models and also the capability to reconstruct associated optimum images with assumed coefficients. 


\title{
International Advanced Research Journal in Science, Engineering and Technology
}

\author{
Vol. 8, Issue 8, August 2021
}

\section{DOI: $10.17148 /$ IARJSET.2021.8819}

\subsubsection{Image computing}

Image computing deals with procedures and mathematical strategies operated on reconstructed imaging information to extract clinically relevant data. These strategies are applied for improvement and analysis of the output image.

\subsubsection{Enhancement}

Image enhancement refines an improved and remodelled illustration of a picture to boost interpretability of the contained data. Its strategies are divided into spacial and frequency domain techniques.

\subsubsection{Analysis}

Image analysis is that the pivotal method in image computing that uses broad forms of strategies which might be classified into 3 main categories: image segmentation, image registration, and image quantification.

\subsubsection{Visualization}

The image method renders image information to visually represent anatomical and physiological imaging data in an exceedingly specific kind over outlined dimensions. Through direct interaction with information, the image is formed each at the initial and intermediate phases of imaging analysis - for instance, to help segmentation and registration processes, and at the output stage to show the refined results.

\subsubsection{Image management}

The final process of medical image processing deals with management of the noninheritable data and encompasses varied techniques for storage, retrieval, and communication of image information. There are many standards and technologies developed to deal with varied aspects of image management. For instance, the medical imaging technology picture archiving and communication system (PACS) provides economical storage and access pictures from multiple modalities and therefore the digital imaging and communication medicine (DICOM) is employed for storing and sending medical images. Special techniques for compression and streaming give economical realization of such performed tasks.

\subsection{Benefits of medical image processing}

The main advantage of image processing is that it permits for in-depth, however non-invasive exploration of internal anatomy. 3D models of the anatomies of interest may be created and studied to boost treatment outcomes for the patient, develop improved medical devices and drug delivery systems, or reach a lot of up-to-date diagnoses. It's become one amongst the key tools leveraged for medical advancement in recent years.

The ever-improving quality of imaging not to mention advanced software package tools facilitates correct digital copies of anatomical structures at varied scales, further like most variable properties as well as bone and soft tissues. activity, applied math analysis, and creation of simulation models that incorporate real anatomical geometries give the chance for a lot of complete understanding patient anatomy and medical devices.

\section{The future- trends and advancement}

A medical device is an equipment that helps stop, diagnose, detect, restore, or treat diseases. As per our specialists and researchers, the long run of medical devices is affected and influenced by the dynamic market and different factors like innovation, growth of rising markets, advent of recent business models, evolving health care delivery models, health information technology (HIT), and effective rules and compliance standards.

The new-age medical technology has reworked the approach of doctor and patient's participation and act with one another. Getting data from over periods of time, past health records, distinctive potential health problems, and making a treatment and setting up measures are all signs of the gradual shift from ancient ways to sensible medical devices. In the long run, medical devices are influenced by technological trends and opportunities that promise to revolutionize the operations of the up-to-date suppliers and also the medical technology firms. The medical device market area is driven by innovation and also the development of progressive medical devices associated technologies has shown a lone growth and advancement within the services.

\subsection{Market Size}

\section{INDIAN MEDICAL DEVICE INDUSTRY REPORT.}

Market Size in India is among the top twenty markets for medical devices worldwide. India's medical devices market stood at US\$ Eleven billion in 2020 and is anticipated to achieve US\$ Sixty-five billion in 2024.The medical devices sector in India contains giant multinationals and midsized firms. The Government of India (GOI) has commenced varied initiatives to strengthen the medical devices sector with stress on research and development (R\&D) and 100\% FDI for medical devices to ramp up the market. From Apr 2000 to Dec 2020, FDI flow within the medical and surgical appliances/devices sector stood at US\$ 18 billion.

\subsection{Export Scenario}

India includes a 75-80\% import dependency on medical devices, with exports at Rs. 14,802 crores (US\$2.1 billion) in 2019 and is anticipated to extend at a Compound annual growth rate (CAGR) of 29\%. 7\% to achieve Rs. 70,490 Crores (US $\$ 10$ billion) in 2025.To increase export of medical devices within the country, the Indian Ministry of Health and Family Welfare (MOHFW) and Central Drugs Standard Control Organisation (CDSCO) enforced the subsequent initiatives: re-examination and implementation of Schedule MIII (a draft steering on smart producing practices and 


\title{
International Advanced Research Journal in Science, Engineering and Technology
}

\author{
Vol. 8, Issue 8, August 2021
}

\section{DOI: $10.17148 / I A R J S E T .2021 .8819$}

facility requirements), system for export labelling, clinical analysis and state licensing authority to increase free sales certificate validity of five years to permit exports, produce an inventory of makers with export licensing for simple access by restrictive authorities worldwide. The Medical Devices Virtual Expo 2021 showcased Indian products and changed direct interaction between Indian suppliers and buyers/importers from other taking part countries. Also, three hundred foreign consumers from the tending sector square measure participated during this event.

\subsection{Investments}

Investments were made to additionally incentivise production of medical devices in 2020, the Govt of India declared incentivisation plans of a minimum of Rs. 3,420 crores (US\$ four.9 billion) over a period of 5 years, and these funds are offered to makers providing an investment in set-ups to manufacture key medical devices by 2022. The Gautam Budh Nagar, Noida, project is anticipated to possess Northern India's 1st medical tools and system producing park. The Park is going to be developed in Sector twenty-eight of the Yamuna motorway Industrial Development Authority (YEIDA) area by the Yamuna motorway Authority. (US\$ 685.35 million), of that Rs.100 Crores by Central Authorities.

\section{CONCLUSION}

Medical devices play a crucial part in patient care. From tongue depressors to chemical diagnostic machines, medical devices embrace a broad and sophisticated part in various discovered technologies. The complexities are let alone power factors in most medical devices. Thus, additionally to the device performance, the crucial side of patient safety and also the health provider's safety gets incorporated, so as to accommodate all safety necessities, meet universal standards and norms are prescribed accordingly. Compliance ensures delivery of the correct technology within the right approach. Thus, product testing brings into existence the primary level of assessment of appropriateness and safety manual of a tool. Medical imaging has seen really exciting advances in recent years. These unreal imaging modalities will currently replicate internal anatomy and dynamic body functions and a good variation of diagnostic and therapeutic procedures will be attainable. However, the development would continue further with the analysis in physics and also in mathematical sciences (e.g., artificial intelligence); fields that have contributed greatly to medical imaging and can keep continued to try and do therefore.

\section{REFERENCES}

1. Privitera, M.B. and J. Johnson. Interconnections of basic science research and product development in medical device design. in Engineering in Medicine and Biology Society, 2009. EMBC 2009. Annual International Conference of the IEEE. 2009.

2. Gilman, B.L., J.E. Brewer, and M.W. Kroll. Medical device design process. in Engineering in Medicine and Biology Society, 2009. EMBC 2009. Annual International Conference of the IEEE. 2009.

3. Hegde, V. Role of human factors / usability engineering in medical device design. in Reliability and Maintainability Symposium (RAMS), 2013 Proceedings - Annual. 2013.

4. Yunqiu, L., et al. Design of interactive medical devices: Feedback and its improvement. in IT in Medicine and Education (ITME), 2011 International Symposium on. 2011.

5. Cauchi, A., et al. Using Medical Device Logs for Improving Medical Device Design. in Healthcare Informatics (ICHI), 2013 IEEE International Conference on. 2013.

6. Privitera, M.B., M. Design, and D.L. Murray. Applied ergonomics: Determining user needs in medical device design. in Engineering in Medicine and Biology Society, 2009. EMBC 2009. Annual International Conference of the IEEE. 2009.

7. Privitera, M.B., M. Design, and D.L. Murray. Applied ergonomics: Determining user needs in medical device design. in Engineering in Medicine and Biology Society, 2009. EMBC 2009. Annual International Conference of the IEEE. 2009.

8. Brown, A., et al. A survey of success factors in New Product Development in the medical devices industry. in Engineering Management Conference, 2008. IEMC Europe 2008. IEEE International. 2008. The Design of Medical Devices ISSN: 2351-8014 Vol. 1 No. 2 , May 2014 134

9. Pazemenas, V., Rapid development for medical products. Instrumentation \& Measurement Magazine, IEEE, $2000.3(2)$ : p. $32-37$.

10. Aguwa, C. and L. Monplaisir. Collaborative architecture framework for the design \& manufacturing of medical devices. in Management of Engineering \& Technology, 2009. PICMET 2009. Portland International Conference on. 2009.

11. Bummo, A. and K. Jung. An Efficient Soft Tissue Characterization Method for Haptic Rendering of Soft Tissue Deformation in Medical Simulation. in Frontiers in the Convergence of Bioscience and Information Technologies, 2007. FBIT 2007. 2007.

12. Kim, J., S. De, and M.A. Srinivasan. Computationally efficient techniques for real time surgical simulation with force feedback. in Haptic Interfaces for Virtual Environment and Teleoperator Systems, 2002. HAPTICS 2002. Proceedings. 10th Symposium on. 2002.

13. Xiufen, Y., et al. Research on soft tissue deformation and cutting in the virtual surgery. in Complex Medical Engineering (CME), 2011 IEEE/ICME International Conference on. 2011.

14. Ling, Z., et al. A real-time deformation modeling scheme of soft tissue for virtual surgical. in Information and Automation (ICIA), 2010 IEEE International Conference on. 2010.

15. Fouladinejad, F. and J.R. Roberts. A computer aided learning package for training users and maintainers of medical equipment. in Engineering in Medicine and Biology Society, 1996. Bridging Disciplines for Biomedicine. Proceedings of the 18th Annual International Conference of the IEEE. 1996.

16. Schimmel, B.J. The Use of Systematic Training To Minimize Risk In Operating Medical Devices. in Policy Issues in Information and Communication Technologies in Medical Applications, 1988. Symposium Record. 1988.

17. Solis, J., et al. Quantitative assessment of the surgical training methods with the suture/ligature training system WKS-2RII. in Robotics and Automation, 2009. ICRA '09. IEEE International Conference on. 2009. 


\section{International Advanced Research Journal in Science, Engineering and Technology}

Vol. 8, Issue 8, August 2021

\section{DOI: $10.17148 / I A R J S E T .2021 .8819$}

18. Ciarkowski, A. FDA regulatory requirements for medical devices with control algorithms. in American Control Conference, 2000. Proceedings of the 2000. 2000.

19. Chanthasopeephan, T., J.P. Desai, and A.C.W. Lau, Modeling Soft-Tissue Deformation Prior to Cutting for Surgical Simulation: Finite Element Analysis and Study of Cutting Parameters. Biomedical Engineering, IEEE Transactions on, 2007. 54(3): p. 349-359.

20. Munzner, R., Regulatory issues. Engineering in Medicine and Biology Magazine, IEEE, 2004. 23(1): p. $207-208$.

21. Mr. Dinesh; Mr. Meiyarasan; Mr. Prabu. "Health Monitoring System Using IOT Sensor". International Research Journal on Advanced Science Hub, 3, 4, 2021, 83-89. doi: 10.47392/irjash.2021.119

22. Karthikeyan A.G.; Kishan K; Pattabiraman M; Prathiv S. "Medical Assistive Robot (MAR)". International Research Journal on Advanced Science Hub, 2, Special Issue ICAMET 10S, 2020, 71-75. doi: 10.47392/irjash.2020.201

23. Salini Suresh; Suneetha V; Niharika Sinha; Sabyasachi Prusty; Sriranga H.A. "Machine Learning: An Intuitive Approach In Healthcare". International Research Journal on Advanced Science Hub, 2, 7, 2020, 67-74. doi: 10.47392/irjash.2020.67

24. Mohan M; Nirmal B J; Sophie Angela R; Nivetha Angel R; Joseph Praveen A. "Securing patient Health Record in Blockchain With Abe Access Control". International Research Journal on Advanced Science Hub, 2, 6, 2020, 145-149. doi: 10.47392/irjash.2020.53

25. Madhamsetty Charitha; Nagaraj G Cholli. "Big Data Analysis and Management in Healthcare". International Research Journal on Advanced Science Hub, 3, Special Issue 7S, 2021, 42-53. 